\title{
Features of eating behavior of children in different age groups
}

\section{Abstract}

Aim: The aim of the present study is to show the features of eating behavior of preadolescents and adolescents with different body mass.

Materials and methods: The study included 249 pre-adolescents aged 8-12years and 314 adolescents aged 13-8years. Body mass index has been calculated for every patient (considering age and gender). In order to assess the eating behavior of the participants, the FEV-II questionnaire self-reports filled out by pre-adolescents aged 8-12 and the Dutch eating behavior questionnaire DEBQ self-reports filled out by adolescents aged 13-18 were analyzed. Statistical analysis was performed using the SPSS.

Results: Among the groups of pre-adolescents and adolescents with normal body mass, the frequency of eating disorders was the same $(75.3 \%, 76.7 \%$ accordingly). The frequency of eating disorders was higher in overweight pre-adolescents aged 8-12 and in obese adolescents. The most prevalent type of eating disorders in each age group is different: external type in adolescents, emotional type in pre-adolescents. With the increase in age and body weight, the frequency of combined type eating disorders was noted to increase as well.

Conclusion: All pre-adolescents and adolescents have eating disorders regardless of body mass. Early diagnosis of the different types of eating behavior has implications for the individual treatment, therapy, and prevention of childhood obesity.

Keywords: pre-adolescentl, adolescent, emotional, external, restrictive eating behavior, weight
Volume 6 Issue I - 2018

\section{Girsh Yana V,Yuditskaya Tatyana A}

Department of Children's Diseases, Medical institute at Surgut State University of KMAO-Ugra, 6284I2, Lenin av, I, Surgut, KMAO-Yugra, Russian Federation

Correspondence: Girsh Yana V, Department of Children's Diseases, Medical institute at Surgut State University of KMAO-Ugra, 6284I2, Lenin av, I, Surgut, KMAO-Yugra, Russian Federation,Tel +79226515916, Email yanaef@yandex.ru

Received: December 01, 2017 | Published: February 08, 2018
Abbreviations: BMI, body mass index; EB, eating behavior; $\mathrm{ED}$, eating disorders; DEBQ-C, dutch eating behaviour questionnaire child version; FEV-II, fragebogen zur erhebung von selbstaussagen zum ernahrungsverhalten; SPSS, statistical package for the social sciences.

\section{Introduction}

Currently, eating disorders (ED) refers to as «diseases of civilization» and the most important component in the development and progression of obesity in all age groups. Many studies conducted in the Americas, Europe, Russia indicate the increasing role of food programming, which is the basis for the formation of ED and determines the characteristics of the metabolism of an individual, the weight of the body and nature of the disease. ${ }^{1,2}$ Various aspects of child nutrition in the first years of life, such as the nature of the introduction of complementary foods, the amount and nature of meals, time and frequency of eating and the formation of food preferences that determine the nature of human nutrition throughout life, have a programming effect and are associated with the risk of several diseases including obesity. ${ }^{3-5}$

Eating behavior (EB) is a set of forms of human behavior, a way of life and actions in various conditions, which include choice, especially food consumption, taking into account its sensory and other properties to provide the body with energy substrates, achieving psychological comfort from her admission, and evaluation of these processes. ED is aimed at meeting the biological, physiological, psychological and social needs of the individual. In this regard, the problems of studying the EB have an independent significance. ${ }^{6-9}$
Eating behavior is influenced by internal and external factors that determine the availability of food, relative to food intake, emotional state and individual experience. ${ }^{10}$

EB is rated as harmonious or deviant. This score is determined by many different parameters: quantitative and qualitative indicators food, feeding, the setting in which the meal and the place that takes the process of eating in the structure of human values. ${ }^{11}$ According to psychosomatic theory, there are three main types of eating disorders: external, emotiogenic and restrictive. External eating behavior is characterized by increased reaction of the individual to external stimuli, which serve as: beautiful table set, dishes, the smell of food, advertising food, but internal incentives to food intake (the level of glycemia, free fatty acids). The importance of the availability to have a food. If children and adolescents with a body weight appropriate to age and sex, response to external food stimuli occurs in a state of hunger, the obese patients such a relationship is violated. Almost all patients with obesity have external manifestations of ED in different degrees of severity, given the slowly emerging and defective sense of fullness. ${ }^{6,12}$ Between patients who have emotiogenic eating behavior, stimulus to meal becomes the emotional component (positive and/or negative emotions), not a hunger. The people with normal body weight in response to negative emotions reduces the feeling of hunger, at that time, as people with obesity respond to negative emotions increased consumption of high-calorie food. ${ }^{13,14}$ For restrictive EB is typical by the appearance of periodic sharp restrictions on meals. The patient is unable to keep himself in food for a long period and he is in a constant stress that leads to failure and decompensation with the development of «diet depression». ${ }^{14,15}$ Consider the complexity of therapy and a 
limited selection of medicinal components in the treatment of obesity the correct estimation of features of eating behavior and its adjustment determines the possibility of achieving more positive long-term effects of therapy. ${ }^{3,15}$

The results of studies of an adult cohort of patients with obesity have shown that disorder weight has more associated with restrictive and emotional types of eating behavior. ${ }^{16}$ In children group the role of each type of ED in the development of obesity is still discussed and depends largely on belonging to age group. . $^{13,14,16}$ The different approaches to meal, choice, volume and nature of food, the time and type of formation of food preferences, the role of parents in different age groups, eating behavior will have features between preadolescents and adolescence. ${ }^{6}$

In recent years, attention of researchers attracts not only the frequency of eating disorders, but also their structure. Investigation of peculiarities of eating behavior in children and adolescence with different body weight are few and contradictory. In the present work the comparative evaluation of the frequency of occurrence of food types of behavior and their combinations in children with different body weight in different age groups. The study used different questionnaires, based on the age, but the types of eating behavior are comparable to the comparative evaluation.

\section{Methodology}

In a prospective comparative study included 656children and adolescents, which were divided into 2 age groups: 249 children aged 8-12years and 314 adolescents 13-18years (Table 1). The sample was formed randomly from among children with different body mass, attending kindergarten and school. Exclusion criteria: children with different forms of secondary obesity, psychiatric disorders, acute states, acute stressful situation in the family and environment.

Table I Comparative evaluation of body weight in different age groups

\begin{tabular}{llll}
\hline Weight & $\begin{array}{l}\text { Children, } \mathbf{n = 2 4 9 ,} \\
\text { Cases/\% }\end{array}$ & $\begin{array}{l}\text { Adolescent, } \mathbf{n = 3} \text { I4, } \\
\text { Cases/\% }\end{array}$ & X2 \\
\hline Normal weight & $158(63,5 \%)$ & $120(38,2 \%)$ & X2 \\
\hline
\end{tabular}

*: Differences between groups on the three indicators are statistically significant

$\wedge$ : Differences between groups statistically significant at $\mathrm{p}<0.05 ; \mathrm{X} 2$ criterion

All children were underwent a physical examination by the standard method. Determination of Body Mass Index (BMI=body weight/height*height), taking into account age and gender. Weight was measured in light clothing, without shoes. Height was also measured according to standard procedures without shoes and hair decorations. To determine whether a child was overweight or obesity international cut-off scores were used. The presence of obesity noted when BMI more than 95\%o, overweight if BMI more than $85 \%$. ${ }^{17,18}$ Abdominal type of obesity was determined with values of waist circumference $\geq 90 \%$ for a given gender and age in adolescents up to 16years, after $16 y e a r s$ used criteria adult patients ( $\geq 94 \mathrm{~cm}$ for boys, $\geq 80 \mathrm{~cm}$ for girls).

In the children group 8-12years, estimation of EB obtained as a result of the analysis of self-reports of children on questionnaire FEV-II (Fragebogen zur Erhebung von Selbstaussagen zum Ernahrungsverhalten. ${ }^{19}$ Eating behavior of adolescent $13-18$ years was assessed using the Dutch eating behavior questionnaire DEBQ (Dutch Eating Behavior Questionnaire). ${ }^{20}$

Statistical analysis was performed using the SPSS, using the Kolmogorov-Smirnov, Shapiro-Wilk test to verify the type of distribution. Consider that the distribution of characteristics of variational series is not consistent with the normal distribution verification of statistical hypotheses was performed using appropriate nonparametric tests. Quantitative data was reflected by the median (Me), interquartile range interval (LQ; UQ) -25-75\%. Binary qualitative characteristics are presented as relative frequencies (\%) and its $95 \%$ confidence interval $(95 \% \mathrm{CI})$. For comparison of the studied groups of patients and in the dynamics was used the Mann-Whitney test (independent samples) and Wilcoxon (dependent samples), analysis of variance (ANOVA) Kruskal- Yollace. Correlation analysis was performed using the nonparametric Spearman rank correlation. For the reliability of differences in qualitative characteristics between the studied groups we used contingency tables with the calculation of $\mathrm{X} 2$. In all cases the null hypothesis was rejected and alternative was accepted when the level of statistical significance $\mathrm{p}<0.05$.

\section{Results}

A group of pre-adolescent children consisted of 249 children (11.06 \pm 0.82 years): 113(45\%) girls and 136(55\%) boys. According to the calculated BMI, the patients were allocated to children with overweight body mass $-36(14,6 \%)$, obesity $-55(22,1 \%)$ and normal weight $158(63,5 \%)$.

The older age group consisted of 314 adolescents with a mean age 14.27 \pm 1.33 : 139 (44\%) girls and 175 (56\%) boys. Assessment of body mass index allowed to identify a group with normal weight $120(38.2 \%)$, the group with overweight and 60adolescents (19.1\%), group with obesity $-134(42.7 \%)$.

In comparable children, groups the number of patients with overweight and obesity increased from younger age group to the oldest $(\mathrm{X} 2=37.2 ; \mathrm{df}=2 ; \mathrm{p}<0.0001)$ (Table 1). Evaluating gender differences in the groups revealed that, regardless of the age group of obese children was dominated by the boys $-55 \%$ and $42.7 \%$, respectively.

Evaluation of the frequency of eating disorders in groups of children and adolescents showed that regardless of body mass all children had eating disorders. Among children and adolescents with normal weight, they met with the same frequency $-75.3 \%$ and $76.7 \%$, respectively. In groups with overweight and obesity, the frequency of ED differed in children aged 8-12years and adolescents. Eating disorders prevailed in the group of children with overweight and among adolescents in the group of obesity (Table 2).

Evaluation of incidence different types of ED also allowed determining the difference between children and adolescents. Emotional type of ED is usually appeared with children 8 -12years old with different body mass in comparison with the same groups of adolescents. External type of ED is registered among adolescents 13-18 years old particularly in 2times frequent than between children. The assessment of the frequency of occurrence of different types of ED, also revealed differences in children and adolescents (Table 3 ). 
Table 2 Frequency of eating disorder among children and adolescents with different body mass

\begin{tabular}{|c|c|c|c|}
\hline Weight, p & $\begin{array}{l}\text { Children, n=249, } \\
\text { Cases } / \%\end{array}$ & $\begin{array}{l}\text { Adolescent, } n=3 \text { |4, } \\
\text { Cases/\% }\end{array}$ & $\mathbf{X} 2$ \\
\hline Normal weight & I 88 (75,3\%) & $\begin{array}{l}24 I(76,7 \%) \\
\times 2\end{array}$ & \\
\hline \multirow[t]{2}{*}{$=0, I, d f=I, p=0,8 I$} & & & $\times 2$ \\
\hline & Overweight & $249(100 \%)$ & $\begin{array}{l}23 I(73,3 \%) \\
\times 2\end{array}$ \\
\hline \multicolumn{4}{|c|}{$=75, I, d f=I, p<0,000 I^{\wedge}$} \\
\hline Obesity & & $172(69 \%)$ & $\begin{array}{l}279(88,8 \%) \\
\times 2\end{array}$ \\
\hline$=32,9, \mathrm{df}=\mathrm{I}, \mathrm{p}<0,00$ & & & \\
\hline
\end{tabular}

*: Differences between groups on the three indicators are statistically significant

^: Differences between groups statistically significant at $\mathrm{p}<0.05, \mathrm{X} 2$ criterion

Table 3 The frequency of various types of eating disorders in children and adolescents with different body mass

\begin{tabular}{|c|c|c|c|c|}
\hline \multirow{2}{*}{ Types of eating behavior } & & \multicolumn{3}{|c|}{ Group, \% (95 \%б CI) } \\
\hline & & Normal weight & over weight & obesity \\
\hline \multirow[b]{2}{*}{ Emotional } & $8-12$ years & $\begin{array}{l}55,1 \\
(47-63)\end{array}$ & $\begin{array}{l}33,3 \\
(18,5-50,9)\end{array}$ & $\begin{array}{l}41,8 \\
(28,6-55,9)\end{array}$ \\
\hline & 13-18years & $\begin{array}{l}23,3 \\
(|6,|-3 \mid, 9)\end{array}$ & $\begin{array}{l}23,3 \\
(13,4-36,0)\end{array}$ & $\begin{array}{l}24,6 \\
(17,6-32,8)\end{array}$ \\
\hline \multirow{2}{*}{ External } & $8-12$ years & $\begin{array}{l}21,5 \\
(15,4-28,7)\end{array}$ & $\begin{array}{l}14,7 \\
(5,2-30,5)\end{array}$ & $\begin{array}{l}10,9 \\
(4, I-22,2)\end{array}$ \\
\hline & 13-18years & $\begin{array}{l}52,5 \\
(43,2-61,7)\end{array}$ & $\begin{array}{l}33,3 \\
(21,7-46,7)\end{array}$ & $\begin{array}{l}26,1 \\
(19-34)\end{array}$ \\
\hline \multirow{2}{*}{ Restrictive } & $8-12$ years & $\begin{array}{l}36,7 \\
(29,2-44,7)\end{array}$ & $\begin{array}{l}100 \\
(90,3-100)\end{array}$ & $\begin{array}{l}52,7 \\
(38,8-66,3)\end{array}$ \\
\hline & |3-18years & $\begin{array}{l}23,3 \\
(|6,|-3 \mid, 9)\end{array}$ & $\begin{array}{l}50 \\
(36,8-63,2)\end{array}$ & $\begin{array}{l}81,3 \\
(73,7-87,5)\end{array}$ \\
\hline Comparison & & $\times 2$ & & \\
\hline $\begin{array}{l}=68,7 \\
\mathrm{df}=6 ; p<0, I^{*}\end{array}$ & $\times 2$ & & & \\
\hline $\begin{array}{l}=64, I ; \\
d f=6 ; p<0, I^{*}\end{array}$ & $\times 2$ & & & \\
\hline $\begin{array}{l}=136,3 ; d f=6 ; \\
p<0, I^{*}\end{array}$ & & & & \\
\hline
\end{tabular}

*Differences between the groups on the three indicators are statistically significant

( $\mathrm{X} 2$ criterion, multiple comparison)

Emotional type was more frequently found in children 8-12years with different body weight in comparison with similar groups of adolescents. External type of eating behavior was observed in adolescents 13-18years, almost 2times more, than in children's group 8 -12years old.

The frequency of occurrence of the external type of eating behavior decreased with increasing body mass in both groups. In the group of teenagers was not found statistically significant correlations for external EB with BMI, while, in the group of children obtained a negative relationship external type EB with such parameters, as BMI $(\mathrm{r}=-0.29 ; \mathrm{p}<0.05)$, body weight $(\mathrm{r}=-0.28 ; \mathrm{p}<0.05)$, waist circumference $(\mathrm{r}=-0.34 ; \mathrm{p}<0.05)$. In the group aged $8-12$ years identified differences at the state restraint of emotions and restrictive types of eating behavior in children with different body mass (X2=11.4; df $=4 ; \mathrm{p}=0.022$ ), (X2=132.2; df=4; $<<0.0001$, respectively), (Table 4). Brat correlation determined the relationship between emotions and restrictive eating behavior $(\mathrm{r}=-.59, \mathrm{p}<0.05)$. 
Table 4 Ball characteristics types of eating behavior in groups of children and adolescents with different body mass

\begin{tabular}{|c|c|c|c|c|c|}
\hline \multirow{2}{*}{\multicolumn{2}{|c|}{ Types of eating behavior }} & \multicolumn{3}{|c|}{ Group, Me(QI-Qh) } & \multirow{2}{*}{ ANOVA } \\
\hline & & Normal weight & Overweight & Obesity & \\
\hline \multirow{2}{*}{ Emotional } & $8-12$ years & $4(2-6)$ & $\begin{array}{l}2(1-5) \\
P<0,025 *\end{array}$ & $3(I-5)$ & $\begin{array}{l}H=6,46 ; \\
P=0,039 \#\end{array}$ \\
\hline & 13-18years & I,3(I,07-I,79) & $\begin{array}{l}\mathrm{I}, 6(\mathrm{I}, \mathrm{I} 5-2,0) \\
\mathrm{P}<0,025^{*}\end{array}$ & $\begin{array}{l}I, 3(I-I, 8) \\
p<0,\left.0\right|^{\wedge}\end{array}$ & $\begin{array}{l}H=3,33 \\
p=0,19\end{array}$ \\
\hline \multirow{2}{*}{ External } & $8-12$ years & $\mathrm{I}(0-3)$ & $\mathrm{I}(0-3)$ & $I(0-2)$ & $\begin{array}{l}H=0,44 \\
p=0,80\end{array}$ \\
\hline & 13-18years & $2,9(1,85-3,7)$ & $\begin{array}{l}2,2(1,7-3,0) \\
p<0,025^{*}\end{array}$ & $\begin{array}{l}2,3(1,9-2,8) \\
p<0,00 I^{*}\end{array}$ & $\begin{array}{l}H=I I, 74 \\
p=0,003 \#\end{array}$ \\
\hline \multirow[b]{2}{*}{ Restrictive } & $8-12$ years & $2,5(I-5)$ & $\begin{array}{l}9(8-10) \\
\mathrm{p}<0,00 I^{*}\end{array}$ & $\begin{array}{l}4(I-5) \\
p^{\prime}<0,\left.00\right|^{\wedge}\end{array}$ & $H=79, \mid 4 ; p=0,0000 \#$ \\
\hline & 13-18years & $\mathrm{I}, 5(\mathrm{I}, 25-\mathrm{I}, 9)$ & $\begin{array}{l}2,4(I, 65-3,55) \\
\mathrm{p}<0,00 I^{*}\end{array}$ & $\begin{array}{l}3, \mathrm{I}(2,6-3,5) \\
\mathrm{P}<0,00 \mathrm{I}^{*} \\
\mathrm{P}<0,00 \mathrm{I}^{\wedge}\end{array}$ & $\begin{array}{l}H=87,74 \\
P=0,000 \#\end{array}$ \\
\hline
\end{tabular}

*: Differences were statistically significant in comparison with the group of children with normal weight

^: Differences were statistically significant in comparison with the group of children with overweight mass (Kolmogorov-Smirnov and Mann-Whitney);

\#: Differences were statistically significant between groups (ANOVA Kruskal-Yoallis)

The null hypothesis was rejected when $\mathrm{p}<0.05$.

In the adolescent group differences were obtained on the frequency of external and restrictive types of $\mathrm{EB}(\mathrm{X} 2=19.7 ; \mathrm{df}=2 ; \mathrm{p}=0.0001$ и $\mathrm{X} 2=85.7 ; \mathrm{df}=2 ; \mathrm{p}<0.0001$, respectively) (Table 4 ). Determined by the reverse correlation between these types of $\mathrm{EB}(\mathrm{r}=-0.23$; $\mathrm{p}<0.05)$.
In the group 8-12years with a normal weight was dominated by the emotional type of EB, in the adolescents group 13-18years - external type EB (Figure 1).

In groups and children and adolescents with overweight and obesity was dominated by a restrictive type of eating behavior (Figures $2 \& 3$ ).

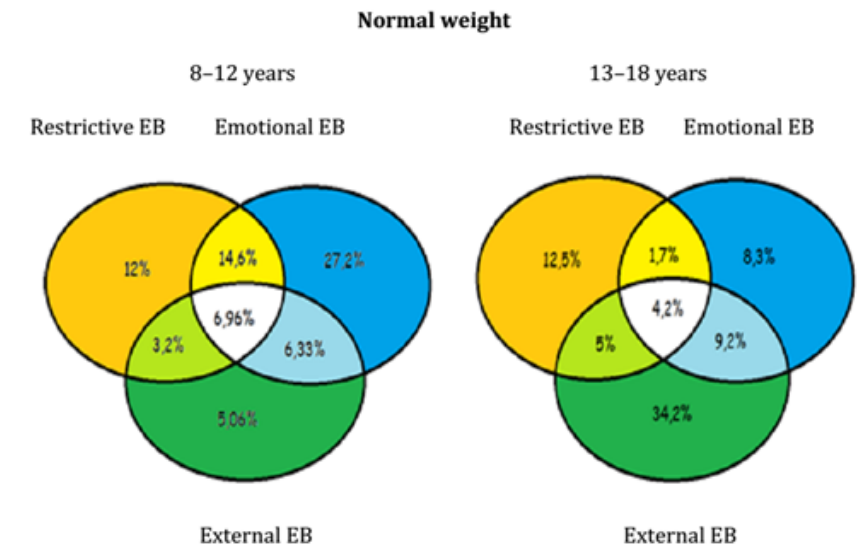

Figure I Structure of eating disorders in children and adolescents with a normal body weight. overweight

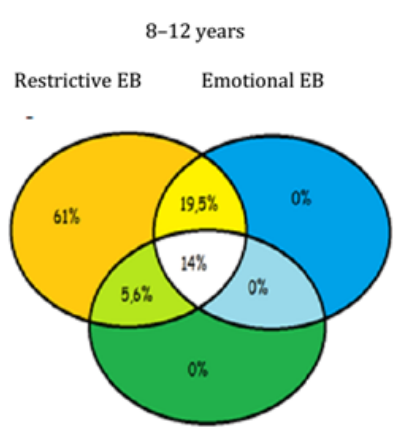

External EB
13-18 years

Restrictive EB Emotional EB

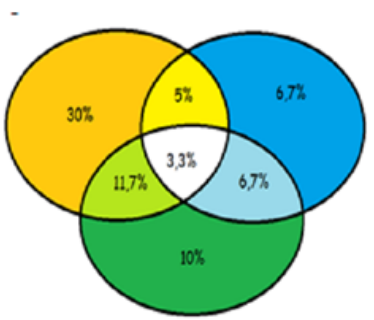

External EB

Figure 2 Structure of eating disorders in children and adolescents with a overweight. 
8-12 years

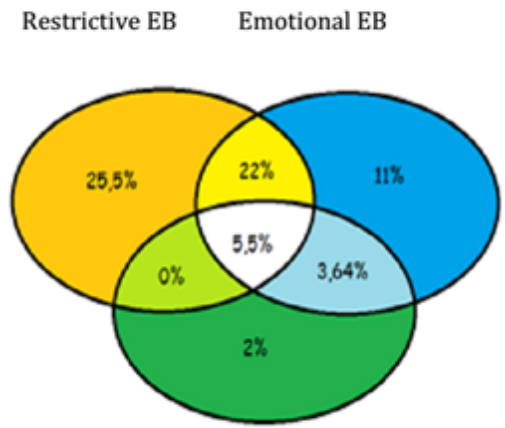

External EB

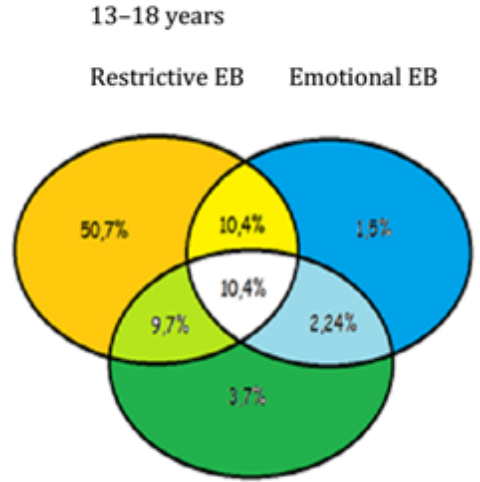

External EB

Figure 3 Structure of eating disorders in children and adolescents with a obesity.

In real clinical practice isolated types of eating behavior are rare. In all groups of patients had combination of several types of EB. With age and with increasing body mass was an increase in the frequency of combined types of ED. In the adolescents group revealed an increase in the frequency of occurrence of a combined ED in patients with overweight and obesity compared with adolescents with normal weight.

In children group 8-12years with normal weight were more often present combined EB (31.1\%), with a predominance of a combination of restrictive and emotional types of EB (14.6\%), in comparison with the adolescents group (20.1\%), which was dominated by a combination of emotional and external types of EB (9.2\%) (Figure 2).

In children group with overweight 8-12years, also occurred more frequently combined $\mathrm{EB}(39 \%)$, with the most frequent combination of restrictive and emotional types of EB (19.5\%), than in the adolescent group $(26.7 \%)$, which was more a combination of restrictive and external eating behavior (11.7\%), (Figure 3). In patients with obesity in all age groups $1 / 3$ (31\% of children; $32.8 \%$ of adolescents) had a combined $\mathrm{EB}$, with a predominance of a combination of restrictive and emotional types (Figure 3). The combination of all 3 types of EB with a higher frequency was detected in children with overweight $(14 \%)$ and adolescents with obesity $(10.4 \%)$.

By comparison of results for pairwise comparison (KolmogorovSmirnov test) between the groups with normal weight and overweight in children 8-12years observed differences in the prevalence of emotional and restrictive types of $\mathrm{EB}$, as adolescents differences were found for all types of EB.

Revealed a direct positive correlation in adolescents' 13-18years old and kids 8-12years old with obesity and overweight with emotional and external types of EB. The children received feedback emotional and restrictive types of EB, adolescents - restrictive and external EB. And in children and adolescents with normal body weight no statistically significant correlations between different types of EB. In groups of obesity in all age one third of patients had combined $\mathrm{EB}$, dominated by a combination of restrictive and emotional types. The tendency is the frequency of this combination in both age groups increased in the groups with increasing body mass.

\section{Limitations}

Our results showed that for children age group 8-12years with overweight and obesity had a restrictive type of EB, that are comparable to studies in Europe and Chile in children in this age group. ${ }^{16,21-23}$ However, in study in children of this age with overweight/ obesity is not obtained correlation restrictive type of EB and BMI, as in a number of works of foreign researches, ${ }^{16,21,24}$ but obtained a negative correlation between external type EB and BMI, which is consistent with their results. ${ }^{21,23}$ In children with overweight/obesity in the age group of 8-12years obtained a higher proportion of children with emotional type of EB than in previously conducted studies..$^{14,16,23}$

Revealed the predominance of a restrictive type of EB in adolescents 13-18 years of age with overweight and obesity, comparable with the findings of other. ${ }^{14,16,24}$ and Russian studies. ${ }^{6,25}$ The increase of severity of restrictive eating behavior does not lead to a permanent reduction of body weight in patients with obesity, which debuted in pubertal period. ${ }^{6,13}$ The high prevalence of external type of eating behavior in adolescents with normal body weight can be considered as a risk factor for possible growth of body mass in adolescence. The obtained results confirmed the results of other studies, who showed that the positive relationship between external type EB and obesity do not occur until adulthood. ${ }^{14}$ In our study, adolescents 13-18years old with overweight/obesity found a negative correlation between restrictive and external $\mathrm{EB}(\mathrm{r}=-.23 ; \mathrm{p}<0.05)$, positive correlation of emotional and external types of $\mathrm{EB}(\mathrm{r}=0.5 ; \mathrm{p}<0.05)$. The revealed tendencies - in both groups - decrease the frequency of the external type EB from group to group with increasing body mass.

\section{Conclusion}

Therefore, the child has certain peculiarities of appetite that interact with environmental factors, affect the formation of eating behavior and body weight. ${ }^{22}$ Detection of early features of appetite, the study of the mechanisms of regulation of eating behavior and their interaction, combining the evaluation of genetic and environmental factors on the development of obesity are promising for further development of effective therapy for obesity in children age group. 


\section{Acknowledgments}

None.

\section{Conflicts of interest}

The authors declare no apparent or potential conflicts of interest related to the publication of this article.

\section{Funding}

None.

\section{References}

1. Meas T. Fetal origins of insulin resistance and the metabolic syndrome: A key role for adipose tissue? Diabetes Metab. 2010;36(1):11-20.

2. Desai M, Beall M, Ross MG. Developmental Origins of Obesity: Programmed Adipogenesis. Curr Diab Rep. 2013;13(1):27-33.

3. Yuditskaya TA, Girsh Ya V. Food behavior of preschool children with different body mass. Nutrition Issues. 2016;6(1):33-40.

4. Robinson S, Fall C. Infant Nutrition and Later Health: A Review of Current Evidence. Nutrients. 2012;4(8):859-874.

5. Guo SS, Wu W, Chumlea WC, et al. Predicting overweight and obesity in adulthood from body mass index values in childhood and adolescence. Am J Clin Nutr. 2002;76(3):653-658.

6. Girsh YaV, Yuditskaya TA. Comparative characteristics of the types of eating behavior in adolescents with different body mass. Bulletin of the Surgu Medicine. 2013;16:35-39.

7. Ahima RS, Antwi DA. Brain regulation of appetite and satiety. Endocrinol Metab Clin North Am. 2008;37(4):811-823.

8. Rodenburg G, Kremers SP, Oenema A, et al. Associations of Children's Appetitive Traits with Weight and Dietary Behaviours in the Context of General Parenting. PLoS One. 2012;7(12):e50642.

9. Carnell S, Wardle J. Measuring behavioural susceptibility to obesity: validation of the child eating behaviour questionnaire. Appetite. 2007;8(1):104-113.

10. O'Rahilly S, Farooqi IS. Human obesity as a heritable disorder of the central control of energy balance. Int J Obes (Lond). 2008;32(Suppl 7):55-61.

11. Sukhorukov DV. Sociological research methods of addictive behavior. Preventive and clinical medicine. 2011;3:61.

12. Schachter S. Obesity and eating. Internal and external cues differentially affect the eating behavior of obese and normal subjects. Science. 1968;161(3843):751-756.
13. Ledoux T, Watson K, Baranowski J, et al. Overeating styles and adiposity among multiethnic youth. Appetite. 2011;56(1):71-77.

14. Snoek HM, Van Strien T, Janssens JM. Emotional, external, restrained eating and overweight in Dutch adolescents. Scand J Psychol. 2007;48(1):23-32.

15. Mitroshina EV, Verbovoi AF. Eating behavior in young men with obesity, manifestiruuschem in adolescence. Obesity and metabolism. 2010;3:32-33.

16. Braet C, Claus L, Goossens L, et al. Differences in eating style between overweight and normal-weight youngsters. $J$ Health Psychol. 2008;13(6):733-743.

17. http://who.int/growthref/who2007_bmi_for_age/en/index.html

18. Cole TJ, Bellizzi MC, Flegal KM, et al. Establishing a standard definition for child overweight and obesity worldwide: international survey. $B M J$. 2000;320(7244):1240-1243.

19. Grunert SC. An Inventory for Self-Testimony on Food Behavior/S.C. Grunert. Diagnostica. 1989;2:167-179.

20. Van Strien T, Frijters J, Bergers G, et al. The Dutch Eating Behavior Questionnaire (DEBQ) for assessment of restrained, emotional, and external eating behavior. Int J Eating Disord. 1986;5(2):295-315.

21. Silva JR, Capurro G, Saumann MP. Problematic eating behaviors and nutritional status in 7 to 12 year-old Chilean children. International Journal of Clinical and Health Psychology. 2013;13(1):32-39.

22. Brunault P, Rabemampianina I, Apfeldorfer G, et al. The Dutch Eating Behavior Questionnaire: Further psychometric validation and clinical implications of the French version in normal weight and obese persons. Presse Med. 2015;44(12 Pt 1):e363-e372.

23. Van Strien T, Osterveld P. The children's DEBQ for assessment of restrained, emotional, and external eating in 7-to 12-year-old children. Int J Eat Disord. 2008;41(1):72-81.

24. Lluch A, Herbeth B, Méjean L, et al. Dietary intakes, eating style and overweight in the Stanislas Family Study. Int J Obes Relat Metab Disord. 2000;24(11):1493-1499.

25. Minyaylova NN. Clinical and metabolic aspects of obesity diagnosis and its different forms in children and adolescents: dis. Dr. med. Sciences (FD of Medisine), Tomsk, Russia. 2012. P. 376.

26. Carnell S, Benson L, Pryor K, et al. Appetitive traits from infancy to adolescence: using behavioral and neural measures to investigate obesity risk. Physiol Behav. 2013;121:79-88. 